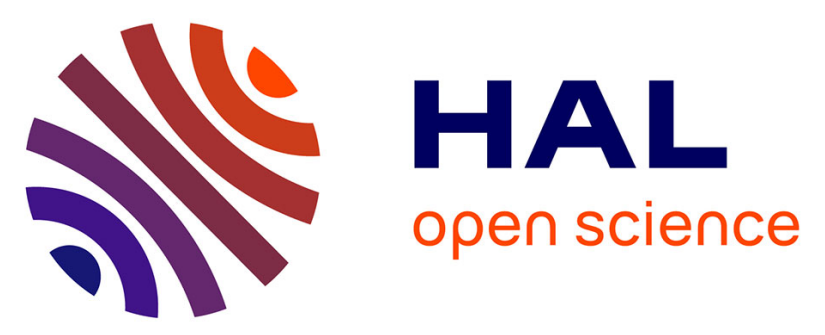

\title{
Role of Cations in the Methane/Carbon Dioxide Partitioning in Nano- and Mesopores of Illite Using Constant Reservoir Composition Molecular Dynamics Simulation
}

Narasimhan Loganathan, A. Ozgur Yazaydin, Geoffrey M. Bowers, Brice F. Ngouana-Wakou, Andrey G. Kalinichev, R. James Kirkpatrick

\section{To cite this version:}

Narasimhan Loganathan, A. Ozgur Yazaydin, Geoffrey M. Bowers, Brice F. Ngouana-Wakou, Andrey G. Kalinichev, et al.. Role of Cations in the Methane/Carbon Dioxide Partitioning in Nanoand Mesopores of Illite Using Constant Reservoir Composition Molecular Dynamics Simulation. J.Phys.Chem.C, 2020, 124 (4), pp.2490-2500. 10.1021/acs.jpcc.9b10051 • hal-02483968

\author{
HAL Id: hal-02483968 \\ https://hal.science/hal-02483968
}

Submitted on 19 Mar 2020

HAL is a multi-disciplinary open access archive for the deposit and dissemination of scientific research documents, whether they are published or not. The documents may come from teaching and research institutions in France or abroad, or from public or private research centers.
L'archive ouverte pluridisciplinaire HAL, est destinée au dépôt et à la diffusion de documents scientifiques de niveau recherche, publiés ou non, émanant des établissements d'enseignement et de recherche français ou étrangers, des laboratoires publics ou privés. 


\title{
Role of Cations in the Methane/Carbon Dioxide Partitioning in Nano- and Mesopores of Illite Using Constant Reservoir Composition Molecular Dynamics Simulation
}

Narasimhan Loganathan,* A. Ozgur Yazaydin, Geoffrey M. Bowers, Brice F. Ngouana-Wakou, Andrey G. Kalinichev, and R. James Kirkpatrick

\begin{abstract}
We performed constant reservoir composition molecular dynamics (CRC-MD) simulations at $323 \mathrm{~K}$ and 124 bar to quantitatively study the partitioning of fluid species between the nano- and mesopores of clay and a bulk reservoir containing an equimolar mixture of $\mathrm{CO}_{2}$ and $\mathrm{CH}_{4}$. The results show that the basal (001) and protonated edge (010) surfaces of illite both demonstrate a strong preference for $\mathrm{CO}_{2}$ over $\mathrm{CH}_{4}$ adsorption; that the (001) surfaces show a stronger preference for $\mathrm{CO}_{2}$ than the (010) surfaces, especially with $\mathrm{K}^{+}$as the exchangeable cation; and that the structuring of the near-surface $\mathrm{CO}_{2}$ by $\mathrm{K}^{+}$is stronger than that by $\mathrm{Na}^{+}$. The protonated (010) surfaces have a somewhat greater

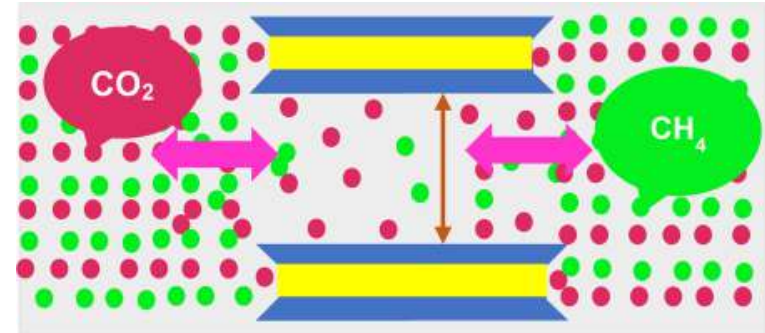
preference for $\mathrm{CH}_{4}$, with the concentration near them close to that in the bulk fluid. The effects of the surfaces on the fluid composition extend to approximately $2.0 \mathrm{~nm}$ from them, with the fluid composition at the center of the pore becoming essentially the same as the bulk composition at a pore thickness of $\sim 5.7 \mathrm{~nm}$. The preference of nano- and mesopores bounded by clay minerals for $\mathrm{CO}_{2}$ over $\mathrm{CH}_{4}$ suggests that injection of $\mathrm{CO}_{2}$ into tight reservoirs is likely to displace $\mathrm{CH}_{4}$ into larger pores, thus enhancing its production.
\end{abstract}

\section{INTRODUCTION}

Natural gas produced from shale and other tight reservoirs is one of the most important resources for addressing increasing global energy demand, and the injection of carbon dioxide into these reservoirs has significant potential to enhance oil and gas recovery and also to facilitate geological carbon sequestration. ${ }^{1-4}$ Clay minerals are important components of shales and other tight formations, ${ }^{5,6}$ and because the pores in these rocks are so small, interaction of the pore fluids (e.g., $\mathrm{H}_{2} \mathrm{O}, \mathrm{CO}_{2}$, and $\mathrm{CH}_{4}$ ) with clay surfaces plays an important role in controlling the structural environments of fluid species, their partitioning between pores of different sizes, and their transport properties. $^{7,8}$ The behavior of water and cations at mineral surfaces and in the nanoscale interlayer galleries of swelling clays has been extensively studied experimentally and by computational molecular simulations, ${ }^{9-20}$ and in recent years, there has been increasing focus on the partitioning of $\mathrm{CO}_{2}$ and $\mathrm{H}_{2} \mathrm{O}$ into expandable clay interlayers and how factors like mineral composition, cation size and charge, and the saturation state of the fluid phase impact the partitioning characteristics. ${ }^{21-41}$ Mixed $\mathrm{CO}_{2} / \mathrm{CH}_{4}$ fluids are of significant potential importance, especially near injection wells, but little is known about their mutual behavior in the nano- and mesopores in shales and other tight formations. Most studies that address $\mathrm{CO}_{2}$ and $\mathrm{CH}_{4}$ interactions are focused on their single-component adsorption in the interlayers of expandable clay minerals (smectites), which show a strong preferential adsorption of $\mathrm{CO}_{2}$ over $\mathrm{CH}_{4} \cdot{ }^{42-45}$

There are only a handful of studies investigating $\mathrm{CO}_{2}$ and $\mathrm{CH}_{4}$ with the surfaces of other minerals, ${ }^{46-48}$ including the nonexpandable, high-charge clay mineral illite, ${ }^{8,49}$ which is a very common component of shales. As for smectites, most studies of illite have focused on the adsorption of singlecomponent fluids species, with the results again demonstrating stronger preference of the basal surfaces for $\mathrm{CO}_{2}$ relative to $\mathrm{CH}_{4}{ }^{46-50}$ Grand canonical Monte Carlo (GCMC) simulations of Zhang et al. $^{47}$ showed that the interaction between $\mathrm{K}^{+}$on the basal surface and $\mathrm{CO}_{2}$ plays an important role in the adsorption of $\mathrm{CO}_{2}$ and that the strength of this interaction decreases with increasing pressure. Similar GCMC studies by Chen et al. ${ }^{46}$ suggested that the quadrupole moment of the $\mathrm{CO}_{2}$ molecules could contribute to their interaction with the oxygen atoms of the basal surfaces of illite. Gibbs ensemble Monte Carlo (GEMC) simulations of mixed $\mathrm{CO}_{2} / \mathrm{CH}_{4}$ fluids interacting with illite basal surfaces by Chong et al. ${ }^{48}$ showed that $\mathrm{CO}_{2}$ strongly interacts with the surface, that the $\mathrm{CO}_{2}$ 


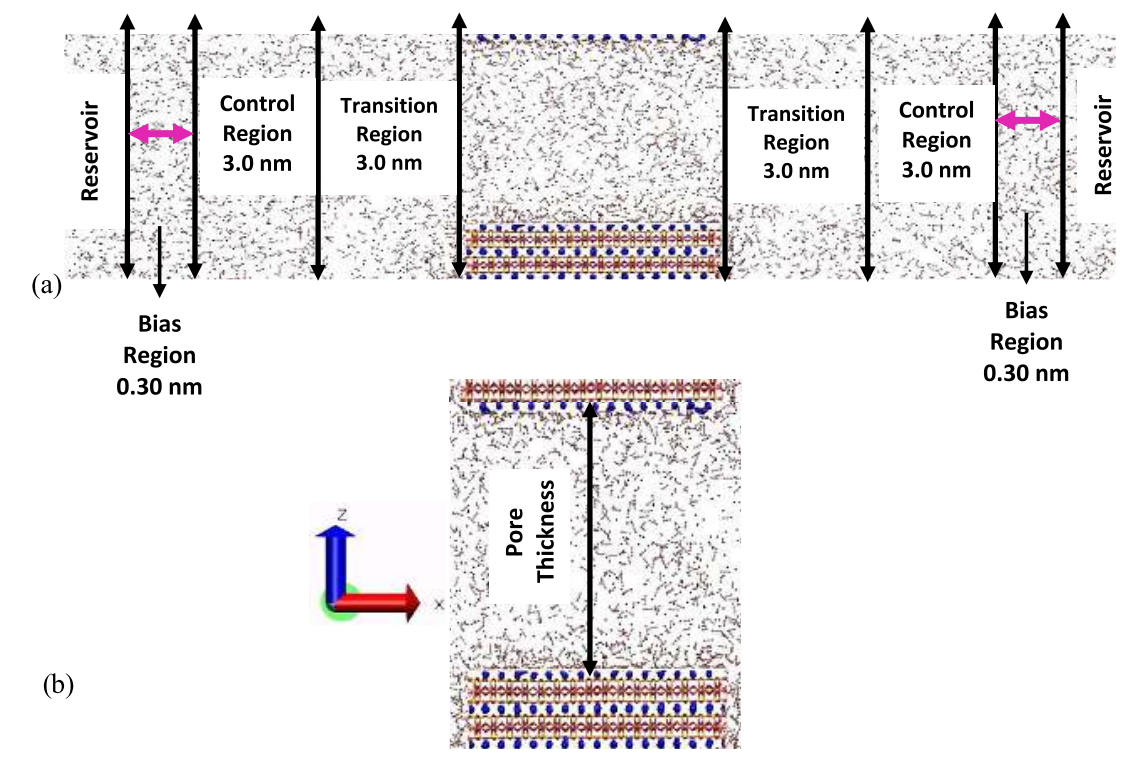

Figure 1. Schematic representation of the simulation cells used in the constant reservoir composition molecular dynamics (CRC-MD) calculations used here to study $\mathrm{CO}_{2} / \mathrm{CH}_{4}$ partitioning into pores bounded by illite basal surfaces. (a) The full simulation cell showing the different regions of the models. (b) Enlarged image of the silt-like pore and finite-sized illite $\mathrm{T}-\mathrm{O}-\mathrm{T}$ layers. Color code: $\mathrm{Si}-\mathrm{yellow}$; $\mathrm{O}-\mathrm{red}$; $\mathrm{Al}-$ pink; $\mathrm{H}-$ white; cations $\left(\mathrm{K}^{+} / \mathrm{Na}^{+}\right)$-blue; $\mathrm{C}_{\mathrm{CO}_{2}}$-cyan; $\mathrm{C}_{\mathrm{CH}_{4}}$-black. Substrate atoms are represented by sticks and the $\mathrm{CO}_{2}$ and $\mathrm{CH}_{4}$ molecules and metal ions are represented by balls. Pink arrows represent the bias forces used to control the fluid composition in the control regions. The directions of $X$ - and $Z$ axes are indicated by the arrows in the lower left.

adsorption increases with decreasing $\mathrm{CH}_{4}$ content in the bulk fluid, and that the surface sorption increases linearly at low pressures $(<20 \mathrm{MPa})$ but reaches a plateau at higher pressures. A recent experimental sorption study by Hwang et al. ${ }^{50}$ also shows stronger interaction between illite and other clay minerals with $\mathrm{CO}_{2}$ than with $\mathrm{CH}_{4}$ at $50{ }^{\circ} \mathrm{C}$ and pressures up to $30 \mathrm{MPa}$. To our knowledge, neither there have been any studies of the impact of pore thickness (distance between the average positions of the centers of basal surface oxygen atoms forming the pore, as shown in Figure 1) and different surface cations on the interaction of $\mathrm{CO}_{2}$ and $\mathrm{CH}_{4}$ with illite, ${ }^{42-50}$ nor have there been any systematic studies of the protonated surfaces of the $\mathrm{T}-\mathrm{O}-\mathrm{T}$ layer broken edge sites, which can contribute significantly to the total surface area of shales. However, recent experiments of Wan et al. ${ }^{49}$ allowed them to hypothesize that the frayed edges of nonswelling clays may be responsible for the unexpectedly high $\mathrm{CO}_{2}$ uptake by such clays.

We recently investigated the effect of pore thickness and edge site vs basal surface on the $\mathrm{CO}_{2} / \mathrm{CH}_{4}$ partitioning and the fluid structure on finite-sized Na-montmorillonite surfaces using constant reservoir composition molecular dynamics (CRC-MD) simulations. ${ }^{51}$ The results showed that $\mathrm{CO}_{2}$ adsorption dominates at both the basal and broken edge surfaces and that the $\mathrm{CO}_{2} / \mathrm{CH}_{4}$ ratio in the pore fluid approaches the bulk value with increasing distance from the surface. In this paper, we present the results of CRC-MD simulations of the partitioning and structural environments of $\mathrm{CO}_{2}$ and $\mathrm{CH}_{4}$ in nano- and mesopores of illite with $\mathrm{K}^{+}$or $\mathrm{Na}^{+}$ as surface charge-compensating ions, quantifying also the differences in the near-surface structure between basal and broken edge surfaces. The results show that the partitioning of $\mathrm{CO}_{2}$ and $\mathrm{CH}_{4}$ between the bulk fluid (representative of the composition in large interparticle pores) and the nano- and mesopores is greatly influenced by the pore thickness and the nature of the charge-balancing cations. Irrespective of the cation, the basal and broken edge surfaces show a stronger preference for $\mathrm{CO}_{2}$ relative to $\mathrm{CH}_{4}$, and the preference is substantially greater than for $\mathrm{Na}$-montmorillonite. ${ }^{51}$

The main objective of our study is to understand the influence of the exchangeable cation on determining the partitioning of supercritical $\mathrm{CO}_{2}$ and $\mathrm{CH}_{4}$ in nano- and mesoconfined pores of the common clay mineral illite. A series of CRC-MD simulation were performed with an equimolar mixture of $\mathrm{CO}_{2} / \mathrm{CH}_{4}$ at $323 \mathrm{~K}$ and 124 bar to address the partitioning behavior using illite particles with the pore thickness ranging from 0.3 to $7.6 \mathrm{~nm}$. In the following section, we introduce the CRC-MD technique, describe how the simulation cell and finite-sized illite particle are constructed, and then describe the simulation details used to carry out this study. In the Results and Discussion section, we present the partitioning of $\mathrm{CO}_{2}$ and $\mathrm{CH}_{4}$ fluids with the increasing pore thickness, discuss their structure, coordination with the exchangeable cations, and their orientation near the pore surfaces. In addition, the effect of broken edge sites in altering the adsorption structure of the fluid species is also investigated. The key important outcomes are summarized in the Conclusions section.

\section{METHODS}

CRC-MD is a novel molecular modeling technique that maintains a constant composition of the fluid in designated volumes external to the pore (Figure 1) by applying selfadjusting bias forces. This method has been used previously to maintain constant chemical potentials of the fluid species in modeling growth of urea crystals ${ }^{52,53}$ and to create a concentration gradient across a membrane (concentration gradient driven $\mathrm{MD}$ ) for modeling gas separation and transport of mixed fluid species. ${ }^{54}$ We have previously discussed the advantages of CRC-MD over hybrid $\mathrm{MC} / \mathrm{MD}$ approaches, such as dual control volume grand canonical molecular dynamics, in maintaining constant external fluid composition 
and for modeling dense fluids in which Monte Carlo exchanges are difficult. ${ }^{54,55}$ Here, each simulation cell is composed of a bulk fluid reservoir, two bias force regions, two composition control regions, two transition regions, and the illite + pore assemblage in the center (Figure 1). The concentration of the fluid species in the control regions is maintained at target values by forces in the bias force regions. These bias forces act in such a way that if the instantaneous concentration of a given species in a control region is different from the target concentration, then molecules are moved from the control region to the reservoir or moved into the control region from it. A detailed explanation of the functional forms of the bias forces and how they work can be found in the Supporting Information and elsewhere. ${ }^{52,54}$ Our simulations used finitesized illite particles with the pore thickness between 0.3 and $7.6 \mathrm{~nm}$ that were placed between the two external reservoirs with an equimolar $\mathrm{CO}_{2} / \mathrm{CH}_{4}$ ratio (Figure 1). The pore thickness is defined as the distance between the average positions of the centers of basal surface oxygen atoms confining the pore (Figure $1 \mathrm{~b}$ ). The reservoir regions contain equimolar mixtures of $\mathrm{CO}_{2}$ and $\mathrm{CH}_{4}$. Thus, both the basal and protonated broken edge surfaces were investigated simultaneously. Surfaces with both $\mathrm{K}^{+}$and $\mathrm{Na}^{+}$were modeled to investigate the effect of $\mathrm{CO}_{2}$ solvation energy of the chargebalancing cation on the fluid behavior. Illite has $\mathrm{K}^{+}$as its most abundant interlayer cation, but it is possible that other cations could exchange onto external surface sites, especially if the fluid is a $\mathrm{NaCl}$-rich brine. ${ }^{56,57}$ The pore dimensions used in our study represent those of interparticle pores between finite-sized illite particles. The interparticle pores can vary from few nanometers to a few hundreds of nanometers, depending upon the arrangement of clay particles. ${ }^{58}$ Based on our previous studies with montmorillonite, ${ }^{51}$ the largest pore thickness (7.6 $\mathrm{nm}$ ) used in our study is sufficient to depict both the nearsurface structure and the fluid structure and composition far from the surface.

The finite-sized illite particle is based on ideal muscovite with the total structural charge reduced $20 \%$ by including less tetrahedral $\mathrm{Al}^{3+}$ for $\mathrm{Si}^{4+}$ substitution. Illite develops its permanent negative structural charge principally by isomorphic substitution of $\mathrm{Al}^{3+}$ for $\mathrm{Si}^{4+}$ in the tetrahedral sheet. The structural formula of our model illite is $\mathrm{M}_{1.6}{ }^{+}\left(\mathrm{Si}_{6.4} \mathrm{Al}_{1.6}\right)\left(\mathrm{Al}_{4}\right)$ $\mathrm{O}_{20}(\mathrm{OH})_{4}{ }^{59}$ The distribution of the $\mathrm{Al}^{3+}$ for $\mathrm{Si}^{4+}$ isomorphic substitution has a quasi-disordered pattern that is in accordance with Lowenstein's rule, which forbids tetrahedral Al-O-Al linkages. ${ }^{60}$ The simulated illite particle has finite lateral dimensions of $\sim 7.30 \mathrm{~nm} \times 4.14 \mathrm{~nm}$ along the crystallographic $a$ and $b$ axes, with an orthorhombic unit cell. To construct the finite-sized particle, the illite structure was cleaved along (010), creating broken edge sites on that surface. The dangling bonds of the tetrahedral $\mathrm{Al}^{3+}$ and $\mathrm{Si}^{4+}$ sites on the broken edges were then saturated with single $\mathrm{OH}^{-}$groups, whereas the dangling octahedral $\mathrm{Al}^{3+}$ sites were saturated with one $\mathrm{OH}^{-}$group and one $\mathrm{H}_{2} \mathrm{O}$ molecule, resulting in a chargeneutral edge surface. This illite particle has one (010) surface exposing some tetrahedral $\mathrm{Al}^{3+}$ sites and one that exposes only tetrahedral $\mathrm{Si}^{4+}$ sites. Further details about the edge site structures can be found elsewhere. ${ }^{51}$

The illite particle is composed of three $\mathrm{T}-\mathrm{O}-\mathrm{T}$ layers and two anhydrous interlayers. It exposes two external basal (001) surfaces to the pore. The total simulated model including the volumes occupied by the fluid has lateral dimensions of 30.0 $\mathrm{nm} \times 4.14 \mathrm{~nm}$ (Figure 1). Because of the three-dimensional periodic boundary conditions employed, only the broken (010) edge surface plane and the basal surfaces bounding the pore are exposed to the fluid. The pore thickness between the external basal surfaces was varied from 0.3 to $7.6 \mathrm{~nm}$. For models with the pore thickness less than $1.0 \mathrm{~nm}$, the chargecompensating cations were placed initially at the midplane of the pores. At larger pore thicknesses, these ions were placed $0.5 \mathrm{~nm}$ from each external basal surface, thereby allowing the cations to choose their preferred adsorption sites during the simulation run. The fluid molecules $\left(\mathrm{CO}_{2}\right.$ and $\left.\mathrm{CH}_{4}\right)$ were initially placed external to the illite particle at distances $>\sim 3.0$ $\mathrm{nm}$ from the two broken (010) surfaces. The total number of fluid molecules in the entire simulation cell increases with the increasing pore thickness to maintain the desired target densities in the control region. The nonswelling illite interlayers contain only $\mathrm{K}^{+}$ions.

The partitioning of $\mathrm{CO}_{2} / \mathrm{CH}_{4}$ and density profiles for each species near the particle surfaces are analyzed in three different dimensions: (i) normal to the basal (001) surfaces bounding the pore ( $z$-direction); (ii) parallel to the broken edges in the transition regions (along the $z$-direction); (iii) normal to the broken (010) edges in the transition region (along the $x$ direction). Similarly, the nominal location of the (010) surfaces is defined as the plane containing the time-averaged positions of the centers of the protonated oxygen atoms on the surface. The orientation of the $\mathrm{CO}_{2}$ molecules and the nearest neighbor coordination among different species on the basal surfaces are analyzed with radial distribution functions (RDFs) and probability density plots. In addition, the total fluid density in the pores confined by basal (001) surfaces is calculated for all pore thickness. In addition, we also calculate the total fluid density which corresponds to the average total number of fluid species $\left(\mathrm{CO}_{2}+\mathrm{CH}_{4}\right)$ over volume within the illite pore region. Note, the volume of finite-sized illite pore region is computed by considering the average positions of the centers of basal (001) surface oxygen atoms bounding the pore in $z$-direction and time-averaged positions of the protonated oxygen atoms on either side of the particle as the lateral boundary limit along $x$-direction $(\sim 7.3 \mathrm{~nm})$, in contrast to actual simulated cell dimensions along $y$-direction $(4.14 \mathrm{~nm})$. Further details about the analysis methods are described elsewhere. ${ }^{34-36,41,51}$

Molecular dynamics simulations in the canonical NVT ensemble at $323 \mathrm{~K}$ were performed using the LAMMPS simulation package. ${ }^{61}$ A Nosé-Hoover thermostat was used to control the temperature. ${ }^{62}$ The interatomic interactions for the illite were obtained from the ClayFF force field, ${ }^{63}$ and the parameters for the broken edge sites were obtained from newly developed metal-O-H bending potentials consistent with ClayFF. $^{64,65}$ The EPM2 ${ }^{66}$ and TraPPE-UA ${ }^{67}$ interaction potentials were used to represent the $\mathrm{CO}_{2}$ and $\mathrm{CH}_{4}$ molecules, respectively. More details about the interaction potentials can be found in the Supporting Information. Three-dimensional periodic boundary conditions were employed. A cutoff of 1.40 $\mathrm{nm}$ was used to compute short-range non-electrostatic interactions, and the long-range electrostatic interactions were computed using the particle-particle-particle-mesh (PPPM) summation algorithm with an accuracy of $10^{-6} \cdot{ }^{68} \mathrm{~A}$ time step of $1 \mathrm{fs}$ was used to integrate the equations of motion. Each system was initially equilibrated for $15 \mathrm{~ns}$, followed by another 2 ns of data production with the atomic coordinates recorded every $10 \mathrm{fs}$. Importantly, the movement of the clay layers with respect to each other was restricted by fixing the 
positions of 18 octahedral $\mathrm{Al}^{3+}$ atoms in the simulated illite structure (six per each TOT layer).

A modified version of the PLUMED 2.3.0 plugin was used to apply the bias forces to maintain the fluid composition in the control regions. ${ }^{69}$ The target $\mathrm{CO}_{2}$ and $\mathrm{CH}_{4}$ densities in the control regions were set to two $\mathrm{CO}_{2}$ and two $\mathrm{CH}_{4}$ molecules/ $\mathrm{nm}^{3}$. At the simulated temperature of $323 \mathrm{~K}$, the reference target densities of fluid species in the control regions correspond to a total fluid pressure of 124 bar, based on the Peng-Robinson equation of state. ${ }^{70}$ These temperature and pressure conditions are relevant to the upper part of the earth's crust and petroleum reservoirs. The width of the transition regions, control regions, and the bias force regions were set to 3.0, 3.0 and $0.30 \mathrm{~nm}$, respectively. The target compositions of the fluid species, $i$, in the control regions were maintained using the force constants $k_{\mathrm{i}}^{\mathrm{L}}=k_{\mathrm{i}}^{\mathrm{R}}=5000 \mathrm{~kJ} \mathrm{~nm}^{3} / \mathrm{mol}$, which are placed at the center of the bias force regions. The compositions in the control regions were monitored at intervals of 0.5 ps during the entire simulation. This procedure maintained the desired composition in the control regions very well (Figure S1).

\section{RESULTS AND DISCUSSION}

Pores Bounded by Basal Surfaces. The mole fraction and number densities of $\mathrm{CO}_{2}$ and $\mathrm{CH}_{4}$ molecules in the pores bounded by the basal (001) surfaces vary greatly with pore thickness (Figure 2a,b). For both the $\mathrm{K}$ - and $\mathrm{Na}$-surfaces, the total fluid density $\left(\frac{N_{\left(\mathrm{CO}_{2}+\mathrm{CH}_{4}\right)}}{\text { volume of illite pore region }}\right)$ increases rapidly
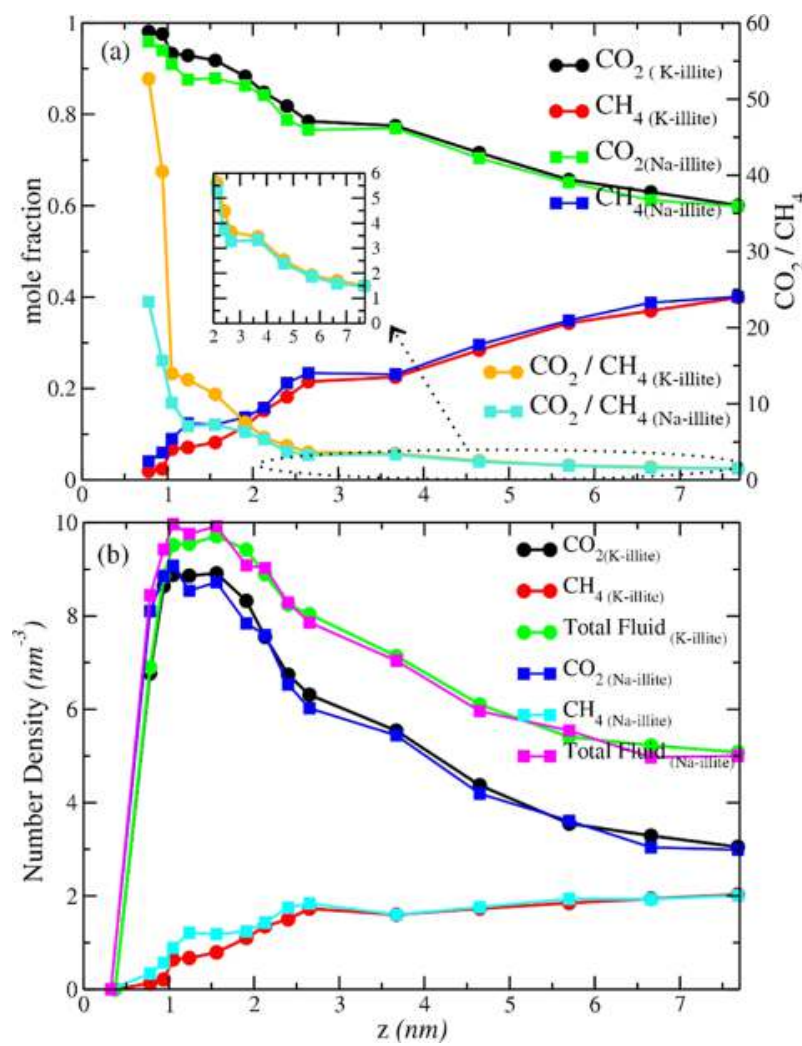

Figure 2. (a) Computed mole fractions of $\mathrm{CO}_{2}$ and $\mathrm{CH}_{4}$ molecules and the $\mathrm{CO}_{2} / \mathrm{CH}_{4}$ ratios with $\mathrm{K}^{+}$and $\mathrm{Na}^{+}$as the exchangeable cation on the pore surfaces as functions of pore thickness for pores bounded by (001) surfaces. (b) Number density of the fluid species confined within these pores as functions of pore thickness. from a pore thickness of $\sim 0.4 \mathrm{~nm}$, reaches a plateau at pore thickness between 1.0 and $1.5 \mathrm{~nm}$, and then decreases with increasing pore thickness. There is a second plateau between 2.5 and $3.5 \mathrm{~nm}$ in the mole fractions for both models. With both cations, at pore thickness less than $1.0 \mathrm{~nm} \mathrm{CO}$ saturates the pore, and there is a negligible amount of $\mathrm{CH}_{4}$. The $\mathrm{CH}_{4}$ molecules that do appear in the pore are concentrated predominantly at the pore openings of the finite illite particle. The $\mathrm{CO}_{2} / \mathrm{CH}_{4}$ ratio does not depend significantly on the exchangeable cation, decreases with increasing pore thickness, and slowly approaches but does not reach the bulk ratio of 2.0 molecules $/ \mathrm{nm}^{3}$ even at a pore thickness of $7.6 \mathrm{~nm}$. The large $\mathrm{CO}_{2} / \mathrm{CH}_{4}$ ratio and its decrease with increasing pore thickness are in good agreement with previous simulations that indicate a favorable energetic interaction of $\mathrm{CO}_{2}$ molecules but not for $\mathrm{CH}_{4}$ molecules with the basal surfaces of illite, ${ }^{46}$ and also parallel the behavior of these species in pores bounded by the smectite clay montmorillonite. ${ }^{51}$

With surface $\mathrm{Na}^{+}$, the results here show that significant $\mathrm{CH}_{4}$ content occurs at $0.75 \mathrm{~nm}$ pore thickness and that its mole fraction increases almost linearly until the first plateau region starting at pore thickness of $1.26 \mathrm{~nm}$ is reached. In contrast, with surface $\mathrm{K}^{+}$, significant amounts of $\mathrm{CH}_{4}$ do not occur until a pore thickness of $1.0 \mathrm{~nm}$. As a result, the $\mathrm{CO}_{2} / \mathrm{CH}_{4}$ ratio with $\mathrm{K}^{+}$is approximately twice that with $\mathrm{Na}^{+}$at a $1.0 \mathrm{~nm}$ pore thickness. At pore thickness $>1.0 \mathrm{~nm}$, the $\mathrm{CH}_{4}$ content with $\mathrm{K}^{+}$ increases gradually, reaches a plateau, and approaches the value with $\mathrm{Na}^{+}$at a pore thickness of $2.2 \mathrm{~nm}$. The number density of $\mathrm{CO}_{2}$ molecules is greater in the illite-bounded pore than in the control region at all pore thicknesses studied, with maximum values of 9.0 and 10.0 at a $1.0 \mathrm{~nm}$ pore thickness with $\mathrm{K}^{+}$and $\mathrm{Na}^{+}$, respectively (Figure $\left.2 \mathrm{~b}\right)$. At larger pore thickness $(z>2.5$ $\mathrm{nm}$ ), the number density of $\mathrm{CO}_{2}$ decreases significantly, in contrast to $\mathrm{CH}_{4}$ which does not change much. Unlike $\mathrm{CO}_{2}$, the number density of $\mathrm{CH}_{4}$ never surpasses the value of 2 molecules $/ \mathrm{nm}^{3}$ in the control region.

These results are in good agreement with previous GCMC simulation studies of K-illite in contact with pure $\mathrm{CO}_{2}$ or pure $\mathrm{CH}_{4}$ at similar thermodynamic conditions ${ }^{46,47}$ and are probably due to the favorable $\mathrm{K}^{+}-\mathrm{CO}_{2}$ solvation energies. ${ }^{71}$ These observed changes strongly suggest that pores with thicknesses of one to a few nanometers bounded by clay surfaces have a significant preference for adsorption of $\mathrm{CO}_{2}$ relative to $\mathrm{CH}_{4}$, with the greatest preference exhibited by nanopores $(<1 \mathrm{~nm})$. Our results are also consistent with adsorption energetics and gas sorption studies that show the clay minerals prefer $\mathrm{CO}_{2}$ over $\mathrm{CH}_{4}$ under anhydrous conditions. ${ }^{50}$ Importantly, our results demonstrate that the exchangeable surface cations affect $\mathrm{CO}_{2} / \mathrm{CH}_{4}$ partitioning only up to pore thickness of few nanometers $(\sim 4)$.

The probability density profiles (PDPs) of $\mathrm{CO}_{2}$ and $\mathrm{CH}_{4}$ normal to the (001) illite surfaces show that the structuring of the fluid species near the pore surfaces is greatly different from $\mathrm{K}^{+}$compared to $\mathrm{Na}^{+}$as the charge-balancing surface cation (Figures 3 and S2). With $\mathrm{K}^{+}$, the PDPs of $\mathrm{CO}_{2}$ show three discernable layers extending up to $\sim 1.8 \mathrm{~nm}$ from the basal surfaces along with a shoulder near $0.4 \mathrm{~nm}$. With $\mathrm{Na}^{+}$there are only three distinguishable layers. With both $\mathrm{K}^{+}$and $\mathrm{Na}^{+}$, the PDPs of $\mathrm{CH}_{4}$ show three layers extending up to $1.5 \mathrm{~nm}$ from the surface. At larger pore thicknesses, the $\mathrm{CO}_{2} / \mathrm{CH}_{4}$ ratios are large near the surface, gradually decrease with increasing distance from the surface, and reach the composition of the control volume at about $2.2 \mathrm{~nm}$ away from the surface. With 

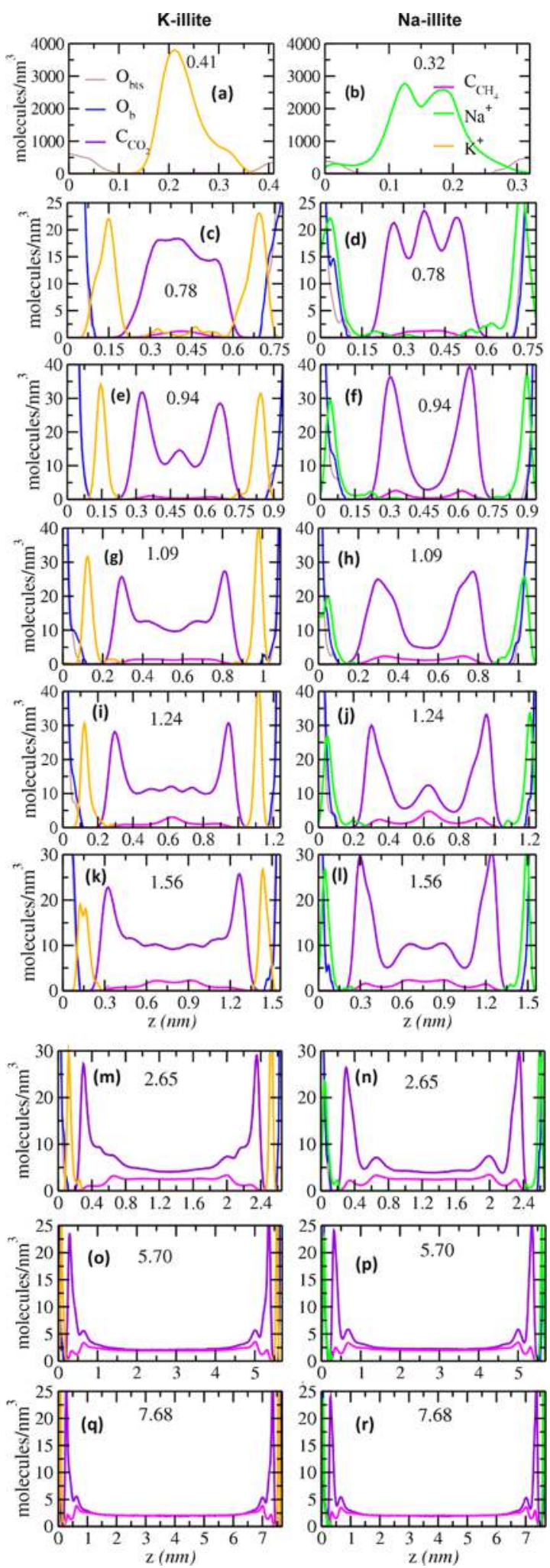

Figure 3. Computed probability density profiles (PDPs) of metal cations $\mathrm{K}^{+}$(orange), $\mathrm{Na}^{+}$(green), $\mathrm{C}_{\mathrm{CO}_{2}}$ (violet) and $\mathrm{C}_{\mathrm{CH}_{4}}$ (magenta) as functions of distance normal to the (001) surfaces of illite with varying pore thicknesses. The vertical brown and blue lines represent the positions of the oxygen atoms of the illite basal surfaces coordinated to tetrahedral Si sites $\left(\mathrm{O}_{\mathrm{b}}\right.$-blue $)$ and tetrahedral $\mathrm{Al}$ sites $\left(\mathrm{O}_{\mathrm{bts}}\right.$ - brown). Left and right columns represent the PDPs of models with exchangeable $\mathrm{K}^{+}$and $\mathrm{Na}^{+}$on the (001) surfaces, respectively.
$\mathrm{K}^{+}$at a pore thickness of $0.78 \mathrm{~nm}$, there is a broad peak for $\mathrm{CO}_{2}$ and a poorly resolved $\mathrm{CH}_{4}$ maximum near the middle of the pore (Figure 3). In contrast, with $\mathrm{Na}^{+}$, there are welldefined peaks for $\mathrm{CO}_{2}$ near each pore surface, a well-defined peak in the center of the pore, and a $\mathrm{CH}_{4}$ density maximum near the center of the pore that is broader than with $\mathrm{K}^{+}$(Figure 3). At a pore thickness of $0.94 \mathrm{~nm}$, there are well-defined first layers of $\mathrm{CO}_{2}$ and $\mathrm{CH}_{4}$ molecules at about $0.3 \mathrm{~nm}$ from the surfaces with both $\mathrm{K}^{+}$and $\mathrm{Na}^{+}$, but the $\mathrm{CH}_{4}$ density is substantially smaller with $\mathrm{K}^{+}$than with $\mathrm{Na}^{+}$. In addition, there is a well-defined peak for $\mathrm{CO}_{2}$ in the center of the pore with $\mathrm{K}^{+}$, but not $\mathrm{Na}^{+}$. At $1.09 \mathrm{~nm}, \mathrm{CO}_{2}$ molecules form two layers at each surface with both $\mathrm{K}^{+}$and $\mathrm{Na}^{+}$, but the second peak with $\mathrm{Na}^{+}$near $0.4 \mathrm{~nm}$ is a less well-resolved shoulder. $\mathrm{CH}_{4}$ forms layers about $0.35-0.38 \mathrm{~nm}$ from the surfaces for both compositions, with those of the $\mathrm{Na}^{+}$system being better resolved. At a pore thickness of $1.24 \mathrm{~nm}$, a third peak for $\mathrm{CO}_{2}$ and a second peak for $\mathrm{CH}_{4}$ near $0.63 \mathrm{~nm}$ begin to form the center of the pore. Importantly, the intensity of the second $\mathrm{CH}_{4}$ peak is greater than that of the first peak with both $\mathrm{K}^{+}$and $\mathrm{Na}^{+}$. At $1.56 \mathrm{~nm}$ there are three peaks or shoulders for $\mathrm{CO}_{2}$ and two peaks for $\mathrm{CH}_{4}$ for both $\mathrm{K}^{+}$and $\mathrm{Na}^{+}$systems.

At pore thicknesses between 1.56 and $2.65 \mathrm{~nm}$, in addition to these peaks, with both $\mathrm{K}^{+}$and $\mathrm{Na}^{+}$on the surface, there are the same near-surface peaks as at smaller pore thicknesses along with a flat distribution for both fluid species in the center of the pores. The $\mathrm{CH}_{4}$ density in the pore center is very similar to that in the control region, whereas the $\mathrm{CO}_{2}$ densities are much greater. At pore thickness $>2.65 \mathrm{~nm}$ with $\mathrm{K}^{+}$, there is a significant change in the structuring of the $\mathrm{CO}_{2}$ molecules, but not the $\mathrm{CH}_{4}$ molecules, near the pore surfaces (Figures 3 and S2). The second peak of $\mathrm{CO}_{2}$ becomes a shoulder on the peak nearest the surface, most likely due to redistribution of $\mathrm{CO}_{2}$ between the near-surface layers. In addition, the $\mathrm{CO}_{2}$ densities in the middle of the pore gradually decrease towards the composition in the control volume. With both $\mathrm{K}^{+}$and $\mathrm{Na}^{+}$as the charge-balancing surface cation, by $5.70 \mathrm{~nm}$ the fluid structuring near the surfaces does not change with further increasing pore thickness, and the $\mathrm{CH}_{4}$ and $\mathrm{CO}_{2}$ densities are essentially the same in the center of the pore. At the largest pore thickness studied $(7.68 \mathrm{~nm})$, with both $\mathrm{K}^{+}$and $\mathrm{Na}^{+}$the $\mathrm{CO}_{2}$ peak maxima are at $0.3,0.67$ and $1.03 \mathrm{~nm}$ from the pore surfaces and there is a shoulder at $0.45 \mathrm{~nm}$ only with $\mathrm{K}^{+}$. In contrast, the peak maxima for $\mathrm{CH}_{4}$ occur at 0.33 and $0.65 \mathrm{~nm}$ with both $\mathrm{K}^{+}$and $\mathrm{Na}^{+}$as surface cations, but the intensity of the $\mathrm{CH}_{4}$ peak at $0.33 \mathrm{~nm}$ is substantially lower with $\mathrm{K}^{+}$than with $\mathrm{Na}^{+}$. The $\mathrm{CH}_{4}$ and $\mathrm{CO}_{2}$ concentrations in the centers of the pores are very close to the composition in the control volume $\left(2\right.$ molecules $/ \mathrm{nm}^{3}$ ). The $\mathrm{CO}_{2}$ and $\mathrm{CH}_{4}$ PDPs with $\mathrm{K}^{+}$ here are substantially different than those for an equimolar $\mathrm{CH}_{4} / \mathrm{CO}_{2}$ ratio in the GEMC studies of Chong et al., ${ }^{48}$ mostly likely due to their use of cation substitution on the octahedral sites, which is not commonly found in natural illites, in contrast to the tetrahedral substitutions used in our work. Their models also had a lower structural charge than ours. Similarly, we attribute the difference in the PDPs of the first layer $\mathrm{CH}_{4}$ with $\mathrm{Na}^{+}$here compared to Na-montmorillonite under the same thermodynamic conditions and fluid composition to the lower structural charge and the octahedral substitution in the montmorillonite. ${ }^{51}$

Irrespective of the exchangeable surface cation, the differences in the structuring of $\mathrm{CO}_{2}$ and $\mathrm{CH}_{4}$ near the pore surfaces in our simulations are due to differences in their interaction 
with the basal surface oxygen atoms. ${ }^{51}$ Clay surfaces clearly prefer $\mathrm{CO}_{2}$ to $\mathrm{CH}_{4}$. The differences in fluid structuring with $\mathrm{K}^{+}$ and $\mathrm{Na}^{+}$, however, are due to differences in the solvation energies of the cations by $\mathrm{CO}_{2}{ }^{70}$ Because $\mathrm{K}^{+}$has a greater affinity toward $\mathrm{CO}_{2}$ than $\mathrm{Na}^{+}$, the increased number of $\mathrm{CO}_{2}$ molecules in the fluid layer nearest the surface with $\mathrm{K}^{+}$restricts $\mathrm{CH}_{4}$ molecules from entering that layer. As with $\mathrm{Na}$ montmorillonite, ${ }^{51}$ there are two $\mathrm{CO}_{2}$ coordination environments on the (001) surface: (i) one $\mathrm{O}_{\mathrm{CO}_{2}}$ located above the center of a ditrigonal cavity and the other $\mathrm{O}_{\mathrm{CO}_{2}}$ located $0.3 \mathrm{~nm}$ above a $\mathrm{Si} / \mathrm{Al}$ tetrahedron and (ii) the $\mathrm{C}_{\mathrm{CO}_{2}}$ relatively close to a tetrahedral $\mathrm{Si} / \mathrm{Al}$ site $(0.45 \mathrm{~nm})$. This fluid structuring is also similar to that of $\mathrm{CO}_{2}$ in the interlayers of smectites. ${ }^{34-36,38}$ In contrast, the absence of a well-resolved $\mathrm{CH}_{4}$ peak in the first layer here shows negligible coordination with the surface. These conclusions are in good agreement with the structure of $\mathrm{CH}_{4}$ in nano- and mesopores of montmorillonite-bounded pores under identical thermodynamic conditions. ${ }^{51}$

The PDPs of the exchangeable cations $\left(\mathrm{K}^{+}\right.$and $\left.\mathrm{Na}^{+}\right)$are greatly influenced by the increasing pore thickness. At collapsed basal spacings (Figure 3 ), the $\mathrm{K}^{+}$ions are located at the midplane of the pore, whereas $\mathrm{Na}^{+}$shows two peaks at $0.13 \mathrm{~nm}$ from each surface. At all other pore thicknesses, there are two peaks for $\mathrm{K}^{+}$and $\mathrm{Na}^{+}$, but their positions are very different. The dominant peak for $\mathrm{K}^{+}$is at $0.17 \mathrm{~nm}$, and the $\mathrm{K}^{+}$ ions are located above the centers of ditrigonal cavities. The minor $\mathrm{K}^{+}$peak at $0.25 \mathrm{~nm}$ is located above $\mathrm{Al}$ tetrahedra. In contrast, due to its smaller size, the dominant $\mathrm{Na}^{+}$peak is at $0.05 \mathrm{~nm}$, and the ions are located at the centers of ditrigonal cavities sharing the same plane as the basal (001) oxygen atoms. The second $\mathrm{Na}^{+}$peak is at $0.20 \mathrm{~nm}$, and these ions are located near the Al tetrahedra. These results are in good agreement with previous simulation studies of $\mathrm{Na}^{+}$on the surfaces of hectorite. ${ }^{13}$ Similarly, the location of the highest $\mathrm{K}^{+}$ peak (at $\sim 0.17 \mathrm{~nm}$ ) is in good agreement with the results of previous simulation studies of muscovite. ${ }^{72}$

The radial distribution functions (RDFs) and running coordination numbers (RCNs) show clearly that both the $\mathrm{K}^{+}$ and $\mathrm{Na}^{+}$ions are essentially all in inner-sphere coordination to the basal oxygen atoms at all pore thicknesses studied (Figure $4 \mathrm{a}, \mathrm{b}$ ). The mean $\mathrm{K}^{+}-\mathrm{O}_{\mathrm{b}}$ and $\mathrm{Na}^{+}-\mathrm{O}_{\mathrm{b}}$ interatomic distances are $\sim 0.28$ and $\sim 0.25 \mathrm{~nm}$, respectively, and do not vary with the varying pore thickness. Similarly, the cation- $\mathrm{O}_{\mathrm{b}} \mathrm{RCNs}$ only increase from 5.2 to $6.0\left(\mathrm{~K}^{+}\right)$and 5.4 to $5.9\left(\mathrm{Na}^{+}\right)$with increasing pore thickness. The RDFs for $\mathrm{CO}_{2}$ show its direct coordination to both cations (Figure $4 \mathrm{c}, \mathrm{d}$ ). Irrespective of the pore thickness, the mean interatomic distances between the cations and the nearest $\mathrm{O}_{\mathrm{CO}_{2}}$ are $\sim 0.30 \mathrm{~nm}$ for $\mathrm{K}^{+}$and $\sim 0.25$ $\mathrm{nm}$ for $\mathrm{Na}^{+}$. Similarly, the cation- $\mathrm{O}_{\mathrm{CO}_{2}} \mathrm{RCNs}$ are $\sim 2.5$ for $\mathrm{K}^{+}$ and $\sim 1.6$ for $\mathrm{Na}^{+}$at all pore thicknesses. None of the models shows significant coordination between $\mathrm{CH}_{4}$ and the exchangeable surface cations, even for short periods of time (Figure 4e,f). The energetically favorable interactions between $\mathrm{K}^{+}$and $\mathrm{CO}_{2}$, along with the larger ionic radius of $\mathrm{K}^{+}$, are responsible for its higher $\mathrm{RCN}$ values compared to $\mathrm{Na}^{+}$, which are in excellent agreement with the relative $\mathrm{CO}_{2}$ solvation energies of the ions and the results of our previous studies of smectites. ${ }^{35,71}$ The interatomic distances between $\mathrm{K}^{+}$and $\mathrm{O}_{\mathrm{b}}$ and $\mathrm{O}_{\mathrm{CO}_{2}}$ are in excellent agreement with previous simulation studies at ambient conditions $(298 \mathrm{~K}) .^{47,72}$
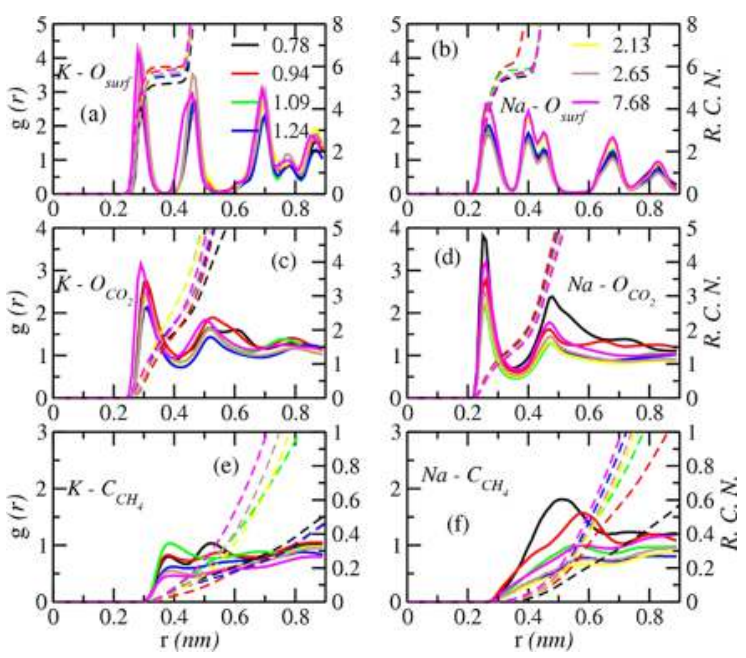

Figure 4. Radial distribution functions (RDFs; solid lines) and the corresponding running coordination numbers (RCNs; dashed lines) of the indicated exchangeable surface cations $\left(\mathrm{K}^{+}\right.$and $\left.\mathrm{Na}^{+}\right)$with the fluid species and the basal oxygen atoms of the illite (001) surface at different pore thickness.

The distributions of $\mathrm{CO}_{2}$ molecular orientations in the first three layers near the (001) surfaces are quite different with $\mathrm{K}^{+}$ and $\mathrm{Na}^{+}$as exchangeable cations, but both change from quite structured in the first layer to nearly isotropic in the third layer. The changes with the changing pore thickness show the greatest structural variability at small pore thicknesses (Figure 5 ). With both $\mathrm{K}^{+}$and $\mathrm{Na}^{+}$, the $\mathrm{CO}_{2}$ molecules in the first layer
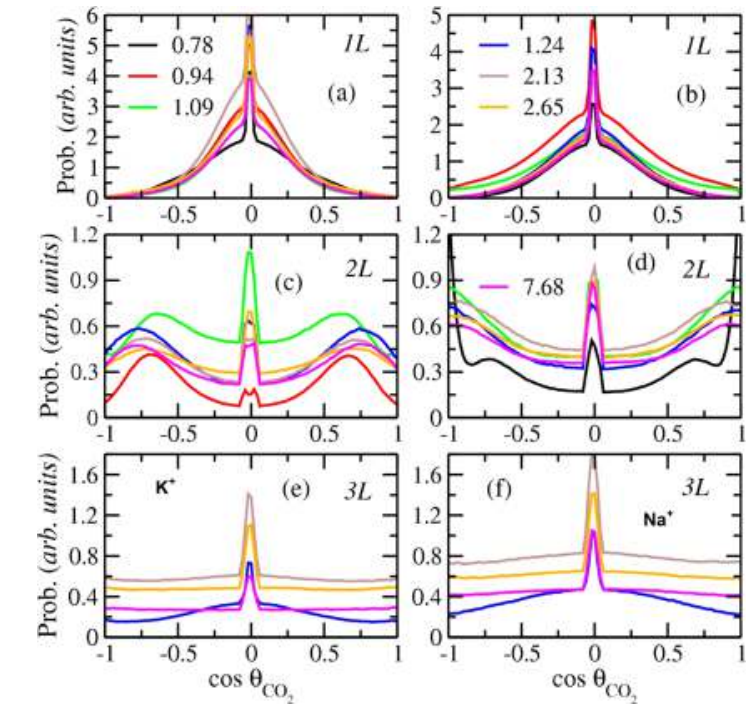

Figure 5. Computed angular distribution of $\mathrm{C}_{\mathrm{CO}_{2}}$ molecules in each of the first three layers near the illite (001) basal surfaces as functions of the pore thickness with $\mathrm{K}^{+}$(left) and $\mathrm{Na}^{+}$(right). $\cos \theta_{\mathrm{CO}_{2}}$ is the cosine of the angle between the $\mathrm{O}-\mathrm{O}$ vector of $\mathrm{CO}_{2}$ molecules and the normal to the (001) surface.

(1L) are oriented predominantly parallel to the basal surface and undergo librational motion around an axis perpendicular to their $\mathrm{O}-\mathrm{C}-\mathrm{O}$ vector (Figure $5 \mathrm{a}, \mathrm{b}$ ). The values of 0 and \pm 1 for $\cos \theta_{\mathrm{CO}_{2}}$ correspond to $\mathrm{CO}_{2}$ orientations parallel and perpendicular to the plane of the basal surface. The broader distributions in the first layer $(1 \mathrm{~L})$ with $\mathrm{Na}^{+}$show that the $\mathrm{CO}_{2}$ 

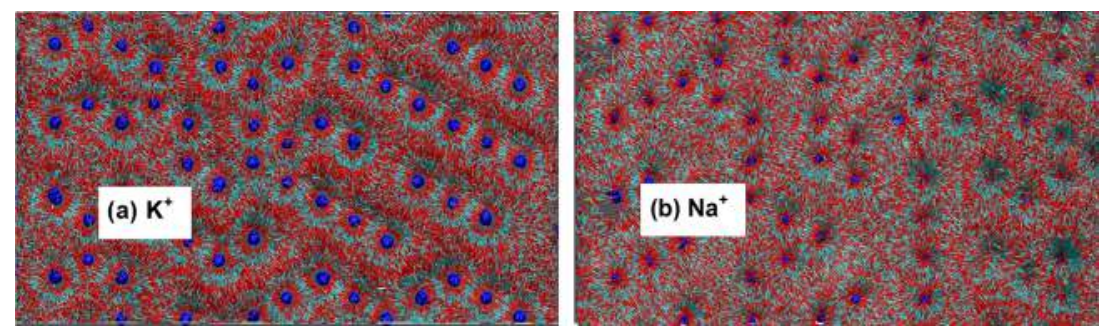

Figure 6. Pictorial representation of relationships between the $\mathrm{CO}_{2}$ molecules in the first fluid layer $\left(0.0-0.35 \mathrm{~nm}\right.$ from the surface) with (a) $\mathrm{K}^{+}$ (left) and (b) $\mathrm{Na}^{+}$(right) at the largest pore thickness studied $(7.68 \mathrm{~nm}$ ). Each image is the sum of 2000 frames in the MD production run and illustrates the structural effects of the greater affinity of $\mathrm{CO}_{2}$ for $\mathrm{K}^{+}$than $\mathrm{Na}^{+}$. Color code: red and cyan sticks represent the $\mathrm{O}$ and $\mathrm{C}$ of $\mathrm{CO}_{2}$, respectively; the exchangeable cations are shown as blue balls.

molecules are in less restricted environments than with $\mathrm{K}^{+}$. The more restricted orientations with $\mathrm{K}^{+}$and the preferred orientation of the $\mathrm{CO}_{2}$ molecules in the first fluid layer with one of their $\mathrm{O}$-atoms toward the $\mathrm{K}^{+}$ions are well-illustrated by the surface maps for the two $7.68 \mathrm{~nm}$ illite models shown in Figure 6. These maps are sums of 2000 individual snapshots in the production runs. Importantly, these orientation distributions at pore thicknesses $<1.0 \mathrm{~nm}$ are in reasonable agreement with the calculated distributions in the interlayers of smectites. ${ }^{34-36,41}$ The $\mathrm{CO}_{2}$ orientation distributions in the second layer $(2 \mathrm{~L})$ are very different with both $\mathrm{K}^{+}$and $\mathrm{Na}^{+}$ (Figure 5c,d), although both have much broader angular distributions than in the first layer. With $\mathrm{K}^{+}$, the $\mathrm{CO}_{2}$ molecules undergo larger wobbling motion of their primary axis with respect to the illite surface normal than in $1 \mathrm{~L}$ and have distributions with average values of $+0.7\left(45^{\circ}\right)$ and -0.7 $\left(135^{\circ}\right)$, along with a small fraction parallel to the surface. In contrast, with $\mathrm{Na}^{+}$at the surface, the maxima in the distributions of the $\mathrm{CO}_{2}$ orientations are parallel (0) and perpendicular $( \pm 1)$ to the basal surfaces. These two orientations suggest that $\mathrm{CO}_{2}$ molecules experience both orientations, with the perpendicular orientation much more probable. In the third layer, with both $\mathrm{K}^{+}$and $\mathrm{Na}^{+}$on the surface, the distributions are nearly isotropic and almost identical (Figure 5e,f). The differences between the $\mathrm{K}^{+}$- and $\mathrm{Na}^{+}$-models in the first two layers are due to the $\mathrm{Na}^{+}$ions being pinned at the center of the ditrigonal cavities at the level of the basal oxygen atoms and the $\mathrm{K}^{+}$ions being on average $0.17 \mathrm{~nm}$ above basal oxygens. In addition to the preference of $\mathrm{CO}_{2}$ for $\mathrm{K}^{+}$relative to $\mathrm{Na}^{+}$, the position of $\mathrm{K}^{+}$limits the accessible, near-surface space for dynamic $\mathrm{CO}_{2}$ reorientation and restricted motion extends into $2 \mathrm{~L}$ (Figure $5 \mathrm{~b}$ ).

Broken Edge Surfaces. The PDPs of $\mathrm{CO}_{2}$ and $\mathrm{CH}_{4}$ on the surfaces of the broken edge (010) surfaces of the clay layers are qualitatively similar to those on the basal (001) surfaces at large pore thicknesses (Figure 7) but are quantitatively different. For both $\mathrm{CO}_{2}$ and $\mathrm{CH}_{4}$, the concentrations in the near-surface layers on the (010) surfaces are greater than in the control volumes, the concentration of $\mathrm{CO}_{2}$ is greater than that of $\mathrm{CH}_{4}$, but the $\mathrm{CO}_{2}$ concentrations are less and the $\mathrm{CH}_{4}$ concentrations more than on the (001) surfaces. This latter result clearly indicates that the affinity of $\mathrm{CO}_{2}$ for the protonated edge sites is weaker than for the basal surfaces. This result is expected because with the chargeneutral protonation state of the modeled (010) surfaces, there are no exchangeable cations on them, and on the (001) surface, interactions between $\mathrm{CO}_{2}$ and the exchangeable cation appear to play a significant role. On the (010) surfaces, $\mathrm{CO}_{2}$ shows two well-defined layers centered at $\sim 0.30$ and $\sim 0.65 \mathrm{~nm}$
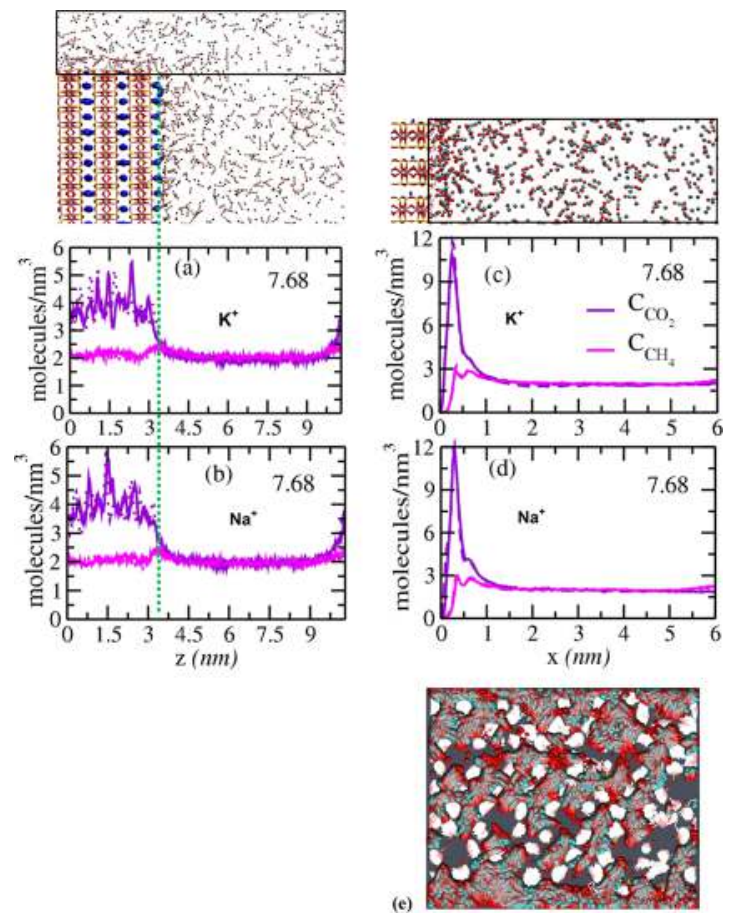

Figure 7. Computed PDPs of $\mathrm{C}_{\mathrm{CO}_{2}}$ (violet) and $\mathrm{C}_{\mathrm{CH}_{4}}$ (magenta) near the broken and protonated (010) surfaces with $\mathrm{K}^{+}$and $\mathrm{Na}^{+}$. The left column represents the average concentrations within $1.50 \mathrm{~nm}$ of the surfaces plotted parallel to them for the pore thicknesses shown at the top of the box. (a) $\mathrm{K}^{+}$and (b) $\mathrm{Na}^{+}$. Solid and dashed lines represent the distributions on the left and right sides of the illite models. Green dotted lines in (a) and (b) represent the plane of basal oxygen atoms of the (010) surface. The right column shows the distributions normal to the (010) surfaces. (c) $\mathrm{K}^{+}$and (d) $\mathrm{Na}^{+}$. (e) The adsorption environments of $\mathrm{CO}_{2}$ molecules in the shoulder region near the protonated (010) surface $(0.0-0.2) \mathrm{nm}$ from the surface, comparable to Figure 6. Red and white sticks represent the protonated edges of the $(010)$ surfaces. $\mathrm{CO}_{2}$ molecules are represented in red $(\mathrm{O})$ and cyan (C).

from the surface, with a poorly resolved shoulder at $\sim 0.15 \mathrm{~nm}$. $\mathrm{CH}_{4}$ shows two layers centered at 0.36 and $0.65 \mathrm{~nm}$, the same distances as on the basal (001) surfaces, corroborating the idea that $\mathrm{CH}_{4}$ adsorption on silicate surfaces is nonspecific. The exchangeable cation has no effect, with the location of the peak maxima and the concentrations essentially identical with both $\mathrm{K}^{+}$and $\mathrm{Na}^{+}$. Similarly, the distributions are essentially identical for surfaces containing both tetrahedral $\mathrm{Al}$ and $\mathrm{Si}$ sites and those with only $\mathrm{Si}$, as we observed previously for montmorillonite with no tetrahedral $\mathrm{Al}$ and mixed octahedral $\mathrm{Al}$ and $\mathrm{Mg}$ sites. $^{51}$ As at the basal (001) surfaces, the increased 
concentrations with respect to the control volume extend to $\sim 2.0 \mathrm{~nm}$ from (010) surfaces (Figure $7 \mathrm{c}, \mathrm{d}$ ). We observe that $\mathrm{CO}_{2}$ molecules in the shoulder region $(\sim 0.15 \mathrm{~nm})$ are adsorbed in narrow channels closer to the fluctuating hydroxyl groups and $\mathrm{H}_{2} \mathrm{O}$ molecules on the (010) edge sites. Figure $7 \mathrm{e}$ (a sum of 2000 individual snapshots in the production run) clearly shows that the volumes probed by $\mathrm{CO}_{2}$ molecules are dictated by the orientation of the (010) edge site groups.

As expected, the fluid structure normal to the (010) edge surfaces is independent of the pore thickness, since these surfaces face the transition region and are the same for each pore thickness investigated. Similarly, the PDPs of the total $\mathrm{CO}_{2}$ within $1.5 \mathrm{~nm}$ of the (010) surfaces also demonstrate the preference of these surfaces for $\mathrm{CO}_{2}$ (Figure 7a,b). In contrast, there is no significant difference in the $\mathrm{CH}_{4}$ concentration in this region and in the control regions. Notably, the composition of the fluid directly above the center of the 7.68 $\mathrm{nm}$ pore is the same as in the control region, as also observed in our previous simulations with montmorillonite. ${ }^{51}$ This result suggests that the distribution of fluid species near broken edges of clay particles is determined primarily by the nature of the cleaved surface and associated protonation state and is not greatly affected by the clay structural charge and the nature of the exchangeable cations.

\section{CONCLUSIONS}

Computational molecular modeling of the interactions of an equimolar mixture of $\mathrm{CO}_{2}$ and $\mathrm{CH}_{4}$ with the external (001) and protonated (010) surfaces of illite with both $\mathrm{K}^{+}$and $\mathrm{Na}^{+}$as the exchangeable cation on the (001) surfaces performed at a temperature of $323 \mathrm{~K}$ and a total fluid pressure of $124 \mathrm{bar}$ shows that these surfaces have a strong preference for $\mathrm{CO}_{2}$ over $\mathrm{CH}_{4}$ as observed in the adsorption energetics and gas sorption experiments. ${ }^{50}$ In general, the results are similar to those of analogous calculations for the smectite mineral $\mathrm{Na}$ montmorillonite. ${ }^{51}$ Together these results suggest that small pores in shales and other tight reservoir rocks bounded by clay minerals greatly prefer $\mathrm{CO}_{2}$ and thus that injection of $\mathrm{CO}_{2}$ into such rocks is likely to displace $\mathrm{CH}_{4}$ from small pores and thereby enhance natural gas production. The calculations were performed using constant reservoir composition molecular dynamics (CRC-MD), which is proving to be a very useful technique to model partitioning of fluid species between a bulk reservoir and nano- and mesopores if the fluid species are mutually soluble. Other important results include the following.

(1) The (001) surfaces show a stronger preference for $\mathrm{CO}_{2}$, especially with $\mathrm{K}^{+}$as the exchangeable cation. The solvation energy of $\mathrm{K}^{+}$by $\mathrm{CO}_{2}$ is known to be stronger than that of $\mathrm{Na}^{+}{ }^{71}$

(2) The protonated (010) surfaces have a somewhat greater preference for $\mathrm{CH}_{4}$ than the (001) surfaces, with the concentration near the surface close to that in the bulk fluid. In contrast, the $\mathrm{CH}_{4}$ concentration in the first fluid layer on the (001) surfaces is less than in the bulk.

(3) The effects of the surfaces on the fluid composition extend to approximately $2.0 \mathrm{~nm}$ from them, and the composition of the fluid in the center of the pore becomes essentially the same as in the bulk at a pore thickness of approximately $5.7 \mathrm{~nm}$.

(4) The orientations of the $\mathrm{CO}_{2}$ molecules near the (001) surfaces vary greatly with distance from the surface and are substantially different for surfaces charge-balanced by $\mathrm{K}^{+}$or $\mathrm{Na}^{+}$. Overall, the results confirm the preference of nano- and mesopores bounded by clay minerals for $\mathrm{CO}_{2}$ over $\mathrm{CH}_{4}$. However, this competitive adsorption of $\mathrm{CO}_{2}$ and $\mathrm{CH}_{4}$ in illites may vary greatly in the presence of $\mathrm{H}_{2} \mathrm{O}$ in natural geological settings because the hydration behavior of the exchangeable cations varies significantly. ${ }^{73}$ Understanding these effects is an objective of future work.

\section{ASSOCIATED CONTENT}

Supporting Information

The Supporting Information is available free of charge at https://pubs.acs.org/doi/10.1021/acs.jpcc.9b10051.

Additional details of the simulation methodology and their functional forms; concentration variation in the left and right control regions for $\mathrm{CO}_{2}$ and $\mathrm{CH}_{4}$ as a function of simulation time in both illite models; details of the planar atomic density distributions of $\mathrm{CO}_{2}$ and $\mathrm{CH}_{4}$ with the increasing pore thickness for both $\mathrm{K}$ - and $\mathrm{Na}$ illites at 001 basal surfaces (PDF)

\section{AUTHOR INFORMATION}

\section{Corresponding Author}

Narasimhan Loganathan - Michigan State University, East Lansing, Michigan; (c) orcid.org/0000-0003-02515430; Phone: (+1)517-353-1106; Email: naresh20@ msu.edu

\section{Other Authors}

A. Ozgur Yazaydin - Michigan State University, East Lansing, Michigan, and University College London, London, United Kingdom; (1) orcid.org/0000-00018562-723X

Geoffrey M. Bowers - St. Mary's College of Maryland, St. Mary's City, Maryland; (1) orcid.org/0000-00034876-9305

Brice F. Ngouana-Wakou - UMR 6457-Institut Mines-Télecom Atlantique, Université de Nantes, CNRS/ IN2P3, Nantes, France

Andrey G. Kalinichev - UMR 6457-Institut MinesTélecom Atlantique, Université de Nantes, CNRS/IN2P3, Nantes, France; (1) orcid.org/0000-0003-0743-4242

R. James Kirkpatrick - Michigan State University, East Lansing, Michigan

Complete contact information is available at: https://pubs.acs.org/10.1021/acs.jpcc.9b10051

\section{Notes}

The authors declare no competing financial interest.

\section{ACKNOWLEDGMENTS}

The authors acknowledge computational resources from the National Energy Research Scientific Computing Center, which is supported by the Office of Science of the U.S. Department of Energy under ECARP No. m1649 and the iCER computational facility at Michigan State University. The work in this manuscript was supported by the Michigan State University Foundation through an MSU Foundation Professorship to R.J.K. A.G.K. and B.F.N.-W. acknowledge financial support of 
the industrial chair "Storage and Disposal of Radioactive Waste" at the IMT-Atlantique, funded by ANDRA, Orano, and EDF, and of the European Union's Horizon 2020 research and innovation program under grant agreement No. 764810.

\section{REFERENCES}

(1) Ilgen, A. G.; Heath, J. E.; Akkutlu, I. Y.; Bryndzia, L. T.; Cole, D. R.; Kharaka, Y. K.; Kneafsey, T. J.; Milliken, K. L.; Pyrak-Nolte, L. J.; Suarez-Rivera, R. Shales at all Scales: Exploring Coupled Processes in Mudrocks. Earth-Sci. Rev. 2017, 166, 132-152.

(2) Pan, Y.; Hui, D.; Luo, P.; Zhang, Y.; Sun, L.; Wang, K. Experimental Investigation of the Geochemical Interactions Between Supercritical $\mathrm{CO}_{2}$ and Shale: Implications of $\mathrm{CO}_{2}$ Storage in GasBearing Shale Formations. Energy Fuels 2018, 32, 1963-1978.

(3) Wilkins, R.; Menefee, A. H.; Clarens, A. F. Environmental Life Cycle Analysis of Water and $\mathrm{CO}_{2}$-Based Fracturing Fluids Used in Unconventional Gas Production. Environ. Sci. Technol. 2016, 50, 13134-13141.

(4) Pei, P.; Ling, K. G.; He, J.; Liu, Z. Z. Shale Gas Reservoir Treatment by a $\mathrm{CO}_{2}$-Based Technology. J. Nat. Gas Sci. Eng. 2015, 26, $1595-1606$.

(5) Gu, M.; Xian, X.; Duan, S.; Du, X. Influences of the Composition and Pore Structure of a Shale on its Selective Adsorption of $\mathrm{CO}_{2}$ over $\mathrm{CH}_{4}$. J. Nat. Gas Sci. Eng. 2017, 46, 296-306.

(6) Godec, M.; Koperna, G.; Petrusak, R.; Oudinot, A. Potential for Enhanced Gas Recovery and $\mathrm{CO}_{2}$ Storage in the Marcellus Shale in the Eastern United States. Int. J. Coal Geol. 2013, 118, 95-104.

(7) Striolo, A.; Cole, D. R. Understanding Shale Gas: Recent Progress and Remaining Challenges. Energy Fuels 2017, 31, 1030010310.

(8) Ho, T. A.; Striolo, A. Water and Methane in Shale Rocks: Flow Pattern Effects on Fluid Transport and Pore Structure. AIChE J. 2015, 61, 2993-2999.

(9) Weiss, C. A.; Kirkpatrick, R. J.; Altaner, S. P. Variations in Interlayer Cation Sites of Clay Minerals as Studied by ${ }^{133} \mathrm{Cs}$ MAS Nuclear Magnetic Resonance Spectroscopy. Am. Mineral. 1990, 75, 970-982.

(10) Bowers, G. M.; Singer, J. W.; Bish, D. L.; Kirkpatrick, R. J. Alkali Metal and $\mathrm{H}_{2} \mathrm{O}$ Dynamics at the Clay/Water Interface. J. Phys. Chem. C 2011, 115, 23395-23407.

(11) Weiss, C. A.; Kirkpatrick, R. J.; Altaner, S. P. The Structural Environments of Cations Adsorbed onto Clays - ${ }^{133}$ Cs VariableTemperature MAS NMR Spectroscopic Study of Hectorite. Geochim. Cosmochim. Acta 1990, 54, 1655-1669.

(12) Morrow, C. P.; Yazaydin, A. O.; Krishnan, M.; Bowers, G. M.; Kalinichev, A. G.; Kirkpatrick, R. J. Structure, Energetics and Dynamics of Smectite Clay Interlayer Hydration: Molecular Dynamics and Metadynamics Investigation of Na-Hectorite. J. Phys. Chem. C 2013, 117, 5172-5187.

(13) Greathouse, J. A.; Hart, D. B.; Bowers, G. M.; Kirkpatrick, R. J.; Cygan, R. T. Molecular Simulation of Structure and Diffusion at Smectite-Water Interfaces: Using Expanded Clay Interlayers as Model Nanopores. J. Phys. Chem. C 2015, 119, 17126-17136.

(14) Loganathan, N.; Yazaydin, A. O.; Bowers, G. M.; Kalinichev, A. G.; Kirkpatrick, R. J. Structure, Energetics and Dynamics of $\mathrm{Cs}^{+}$and $\mathrm{H}_{2} \mathrm{O}$ in Hectorite: Molecular Dynamics Simulations with Unconstrained Substrate Surface. J. Phys. Chem. C 2016, 120, 10298-10310.

(15) Teich-McGoldrick, S. L.; Greathouse, J. A.; Colon, C. F.; Cygan, R. T. Swelling Properties of Montmorillonite and Beidellite Clay Minerals from Molecular Simulation: Comparison of Temperature, Interlayer Cation, and Charge Location Effects. J. Phys. Chem. C 2015, 119, 20880-20891.

(16) Loganathan, N.; Yazaydin, A. O.; Bowers, G. M.; Kalinichev, A. G.; Kirkpatrick, R. J. Cation and Water Structure, Dynamics and Energetics in Smectite Clays: A Molecular Dynamics Study of CaHectorite. J. Phys. Chem. C 2016, 120, 12429-12439.

(17) Reddy, U. V.; Bowers, G. M.; Loganathan, N.; Bowden, M.; Yazaydin, A. O.; Kirkpatrick, R. J. Water Structure and Dynamics in
Smectites: ${ }^{2} \mathrm{H}$ NMR Spectroscopy of $\mathrm{Mg}, \mathrm{Ca}, \mathrm{Sr}, \mathrm{Cs}$ and $\mathrm{Pb}-$ Hectorite. J. Phys. Chem. C 2016, 120, 8863-8876.

(18) Bowers, G. M.; Singer, J. W.; Bish, D. L.; Kirkpatrick, R. J. Structure and Dynamical Relationships of $\mathrm{Ca}^{2+}$ and $\mathrm{H}_{2} \mathrm{O}$ in Smectite $/{ }^{2} \mathrm{H}_{2} \mathrm{O}$ Sytems. Am. Mineral. 2014, 99, 318-331.

(19) Nanda, R.; Bowers, G. M.; Loganathan, N.; Burton, S. D.; Kirkpatrick, R. J. Temperature Dependent Structure and Dynamics in Smectite Interlayers: ${ }^{23} \mathrm{Na}$ MAS Spectroscopy of Na-Hectorite. RSC Adv. 2019, 9, 12755-12765.

(20) Loganathan, N.; Kalinichev, A. G. Quantifying the Mechanisms of Site-Specific Ion Exchange at an Inhomogeneously Charged Surface: Case of $\mathrm{Cs}^{+} / \mathrm{K}^{+}$on Hydrated Muscovite Mica. J. Phys. Chem. C 2017, 121, 7829-7836.

(21) Schaef, H. T.; Loring, J. S.; Glezakou, V. A.; Miller, Q. R. S.; Chen, J.; Owen, A. T.; Lee, M.-S.; Ilton, E. S.; Felmy, A. R.; McGrail, B. P.; et al. Competitive Sorption of $\mathrm{CO}_{2}$ and $\mathrm{H}_{2} \mathrm{O}$ in 2:1 Layer Phyllosilicates. Geochim. Cosmochim. Acta 2015, 161, 248-257.

(22) Loring, J. S.; Schaef, H. T.; Turcu, R. V. F.; Thompson, C. J.; Miller, Q. R.; Martin, P. F.; Hu, J.; Hoyt, D. W.; Qafoku, O.; Ilton, E. S.; et al. In Situ Molecular Spectroscopic Evidence for $\mathrm{CO}_{2}$ Intercalation into Montmorillonite in Supercritical Carbon Dioxide. Langmuir 2012, 28, 7125-7128.

(23) Loring, J. S.; Ilton, E. S.; Chen, J.; Thompson, C. J.; Martin, P. F.; Benezeth, P.; Rosso, K. M.; Felmy, A. R.; Schaef, H. T. In Situ Study of $\mathrm{CO}_{2}$ and $\mathrm{H}_{2} \mathrm{O}$ Partitioning Between Na-Montmorillonite and Variably Wet Supercritical Carbon Dioxide. Langmuir 2014, 30, $6120-6128$.

(24) Loring, J. S.; Schaef, H. T.; Thompson, C. J.; Turcu, R. V. F.; Miller, Q. R.; Chen, J.; Hu, J.; Hoyt, D. W.; Martin, P. F.; Ilton, E. S.; et al. Clay Hydration/Dehydration in Dry to Water-Saturated Supercritical $\mathrm{CO}_{2}$ : Implications for Caprock Integrity. Energy Procedia 2013, 37, 5443-5448.

(25) Botan, A.; Rotenberg, R.; Marry, V.; Turq, P.; Noetinger, B. Carbon Dioxide in Montmorillonite Clay Hydrates: Thermodynamics, Structure and Transport from Molecular Simulation. J. Phys. Chem. C 2010, 114, 14962-14969.

(26) Kadoura, A.; Nair, A. K. N.; Sun, S. Molecular Simulation Study of Montmorillonite in Contact with Variably Wet Supercritical Carbon Dioxide. J. Phys. Chem. C 2017, 121, 6199-6208.

(27) Makaremi, M.; Jordan, K. D.; Guthrie, G. D.; Myshakin, E. M. Multiphase Monte Carlo and Molecular Dynamics Simulations of Water and $\mathrm{CO}_{2}$ Intercalation in Montmorillonite and Beidellite. J. Phys. Chem. C 2015, 119, 15112-15124.

(28) Rao, A.; Leng, Y. Effect of Layer Charge on $\mathrm{CO}_{2}$ and $\mathrm{H}_{2} \mathrm{O}$ Intercalations in Swelling Clays. Langmuir 2016, 32, 11366-11374.

(29) Sena, M. M.; Morrow, C. P.; Kirkpatrick, R. J.; Krishnan, M. Structure, Energetics, and Dynamics of Supercritical Carbon Dioxide at Smectite Mineral-Water Interfaces: Molecular Dynamics Modeling and Adaptive Force Investigation of $\mathrm{CO}_{2} / \mathrm{H}_{2} \mathrm{O}$ Mixtures Confined in Na-Montmorillonite. Chem. Mater. 2015, 27, 6946-6959.

(30) Yazaydin, A. O.; Bowers, G. M.; Kirkpatrick, R. J. Molecular Dynamics Modeling of Carbon Dioxide, Water and Natural Organic Matter in Na-Hectorite. Phys. Chem. Chem. Phys. 2015, 17, 2335623367.

(31) Cole, D. R.; Chialvo, A. A.; Rother, G.; Vlcek, L.; Cummings, P. T. Supercritical Fluid Behavior at Nanoscale Interfaces: Implications for $\mathrm{CO}_{2}$ Sequestration in Geological Formations. Philos. Mag. 2010, 90, 2339-2363.

(32) Cole, D. R.; Ok, S.; Striolo, A.; Phan, A. Hydrocarbon Behavior at Nanoscale Interfaces. Rev. Mineral. Geochem. 2013, 75, 495-545.

(33) Rother, G.; Ilton, E. S.; Wallacher, D.; Hauss, T.; Schaef, H. T.; Qafoku, O.; Rosso, K. M.; Felmy, A. R.; Krukowski, E. G.; Stack, A. G.; et al. $\mathrm{CO}_{2}$ Sorption to Subsingle Hydration Layer Montmorillonite Clay Studies by Excess Sorption and Neutron Diffraction Measurements. Environ. Sci. Technol. 2013, 47, 205-211.

(34) Loganathan, N.; Yazaydin, A. O.; Bowers, G. M.; Kalinichev, A. G.; Kirkpatrick, R. J. Molecular Dynamics Study of $\mathrm{CO}_{2}$ and $\mathrm{H}_{2} \mathrm{O}$ Intercalation in Smectite Clays: Effect of Temperature and Pressure 
on Interlayer Structure and Dynamics in Hectorite. J. Phys. Chem. C 2017, 121, 24527-24540.

(35) Loganathan, N.; Bowers, G. M.; Yazaydin, A. O.; Schaef, H. T.; Loring, J.; Kalinichev, A. G.; Kirkpatrick, R. J. Clay Swelling in Dry Supercritical Carbon Dioxide: Effects of Interlayer Cations on the Structure, Dynamics and Energetics of $\mathrm{CO}_{2}$ Intercalation Probed by XRD, NMR and GCMD Simulations. J. Phys. Chem. C 2018, 122, 4391-4402.

(36) Loganathan, N.; Bowers, G. M.; Yazaydin, A. O.; Kalinichev, A. G.; Kirkpatrick, R. J. Competitive Adsorption of $\mathrm{H}_{2} \mathrm{O}$ and $\mathrm{CO}_{2}$ in 2Dimensional Nanoconfinement: GCMD Simulations of Cs- and CaHectorites. J. Phys. Chem. C 2018, 122, 23460-23469.

(37) Bowers, G. M.; Schaef, H. T.; Loring, J. S.; Hoyt, D. W.; Burton, S. D.; Walter, E. D.; Kirkpatrick, R. J. Role of Cations in $\mathrm{CO}_{2}$ Adsorption, Dynamics and Hydration in Smectite Clays under In Situ Supercritical $\mathrm{CO}_{2}$ Conditions. J. Phys. Chem. C 2017, 121, 577-592. (38) Schaef, H. T.; Loganathan, N.; Bowers, G. M.; Kirkpatrick, R.; Yazaydin, A. O.; Burton, S. D.; Hoyt, D. W.; Ilton, E. S.; Thanthiriwatte, K. S.; Dixon, D. A.; et al. Tipping Point for Expansion of Layered Aluminosilicates in Weakly Polar Solvents: Supercritical $\mathrm{CO}_{2}$. ACS Appl. Mater. Interfaces 2017, 9, 36783-36791.

(39) Bowers, G. M.; Loring, J. S.; Schaef, H. T.; Walter, E. D.; Burton, S. D.; Hoyt, D. W.; Cunniff, S. S.; Loganathan, N.; Kirkpatrick, R. J. Interaction of Hydrocarbons with Clays under Reservoir Conditions: In Situ Infrared and Nuclear Magnetic Resonance Spectroscopy and X-ray Diffraction for Expandable Clays with Variably Wet Supercritical Methane. ACS Earth Space Chem. 2018, 2, 640-652.

(40) Giesting, P.; Guggenheim, S.; van Groos, A. F. K.; Busch, A. Interaction of Carbon Dioxide with $\mathrm{Na}$-Exchanged Montmorillonite at Pressures to 640 bar: Implications for $\mathrm{CO}_{2}$ Sequestration. Int. J. Greenhouse Gas Control 2012, 8, 73-81.

(41) Loganathan, N.; Yazaydin, A. O.; Kirkpatrick, R. J.; Bowers, G. M. Tuning the Hydrophobicity of Layer-Structure Silicates to Promote Adsorption of Non-Aqueous Fluids: Effects of F- and $\mathrm{OH}-$ Substitution on $\mathrm{CO}_{2}$ Partitioning into Smectite Interlayers. J. Phys. Chem. C 2019, 123, 4848-4855.

(42) Jin, Z.; Firoozabadi, A. Methane and Carbon Dioxide Adsorption in Clay-like Slit Pores by Monte Carlo Simulations. Fluid Phase Equilib. 2013, 360, 456-465.

(43) Jin, Z.; Firoozabadi, A. Effect of Water on Methane and Carbon Dioxide Sorption in Clay Minerals by Monte Carlo Simulations. Fluid Phase Equilib. 2014, 382, 10-20.

(44) Yang, N.; Liu, S.; Yang, X. Molecular Simulation of Preferential Adsorption of $\mathrm{CO}_{2}$ over $\mathrm{CH}_{4}$ in Na-montmorillonite Clay Mineral. Appl. Surf. Sci. 2015, 356, 1262-1271.

(45) Wang, Q.; Huang, L. Molecular Insight into Competitive Adsorption of Methane and Carbon Dioxide in Montmorillonite: Effect of Clay Structure and Water Content. Fuel 2019, 239, 32-43.

(46) Chen, G.; Lu, S.; Liu, K.; Han, T.; Xu, C.; Xue, Q.; Shen, B.; Guo, Z. GCMC Simulations on the Adsorption Mechanisms of $\mathrm{CH}_{4}$ and $\mathrm{CO}_{2}$ in $\mathrm{K}$-illite and their Implications for Shale Gas Exploration and Development. Fuel 2018, 224, 521-528.

(47) Zhang, J.; Clennell, M. B.; Liu, K.; Pervukhina, M.; Chen, C.; Dwhurst, D. N. Methane and Carbon Dioxide Adsorption on Illite. Energy Fuels 2016, 30, 10643-10652.

(48) Chong, L.; Myshakin, E. M. Molecular Simulations of Competitive Adsorption of Carbon Dioxide - Methane Mixture on Illitic Clay Surfaces. Fluid Phase Equilib. 2018, 472, 185-195.

(49) Wan, J.; Tokunaga, T. K.; Ashby, P. D.; Kim, Y.; Voltolini, M.; Gilbert, B.; DePaolo, D. J. Supercritical $\mathrm{CO}_{2}$ Uptake by Nonswelling Phyllosilicates. Proc. Natl. Acad. Sci. 2018, 115, 873-878.

(50) Hwang, J.; Pini, R. Supercritical $\mathrm{CO}_{2}$ and $\mathrm{CH}_{4}$ Uptake by IlliteSmectite Clay Minerals. Environ. Sci. Technol. 2019, 53, 1158811596.

(51) Loganathan, N.; Bowers, G. M.; Wakou, B. F. W.; Kalinichev, A. G.; Kirkpatrick, R. J.; Yazaydin, A. O. Understanding Methane/ Carbon Dioxide Partitioning in Clay Nano- and Meso-pores with
Constant Reservoir Composition Molecular Dynamics Modeling. Phys. Chem. Chem. Phys. 2019, 21, 6917-6924.

(52) Perego, C.; Salvalaglio, M.; Parrinello, M. Molecular Dynamics Simulation of Solutions at Constant Chemical Potential. J. Chem. Phys. 2015, 142, No. 144113.

(53) Karmakar, T.; Piaggi, P. M.; Perego, C.; Parrinello, M. A Cannibalistic Approach to Grand Canonical Crystal Growth. J. Chem. Theory Comput. 2018, 14, 2678-2683.

(54) Ozcan, A.; Perego, C.; Salvalaglio, M.; Parrinello, M.; Yazaydin, O. Concentration Gradient Driven Molecular Dynamics: A New Method for Simulations of Membrane Permeation and Separation. Chem. Sci. 2017, 8, 3858-3865.

(55) Heffelfinger, G. S.; van Swol, F. Diffusion in Lennard-Jones Fluids Using Dual Control Volume Grand Canonical Molecular Dynamics Simulation (DCV-GCMD). J. Chem. Phys. 1994, 100, 7548.

(56) $\mathrm{Hu}$, Y.; Ray, J. R.; Jun, Y.-S. $\mathrm{Na}^{+}, \mathrm{Ca}^{2+}$, and $\mathrm{Mg}^{2+}$ in Brines Affect Supercritical $\mathrm{CO}_{2}$-Brine-Biotite Interactions: Ion Exchange, Biotite Dissolution, and Illite Precipitation. Environ. Sci. Technol. 2013, 47, 191-197.

(57) Farajzadeh, R.; Guo, H.; Winden, J.; Bruining, J. Cation Exchange in the Presence of Oil in Porous Media. ACS Earth Space Chem. 2017, 1, 101-112.

(58) Rotenberg, B. Water in Clay Nanopores. MRS Bull. 2014, 39, 1074-1081.

(59) Altaner, S. P.; Weiss, C. A.; Kirkpatrick, R. J. Evidence from ${ }^{29} \mathrm{Si}$ NMR for the Structure of Mixed-Layer Illite/Smectite Clay Minerals. Nature 1988, 331, 699-702.

(60) Lowenstein, W. The Distribution of Aluminium in the Tetrahedra of Silicates and Aluminates. Am. Mineral. 1954, 39, 9296.

(61) Plimpton, S. Fast Parallel Algorithms for Short-Range Molecular Dynamics. J. Comput. Phys. 1995, 117, 1-19.

(62) Hoover, W. G. Canonical Dynamics: Equilibrium Phase-Space Distributions. Phys. Rev. A 1985, 31, 1695-1697.

(63) Cygan, R. T.; Liang, J.-J.; Kalinichev, A. G. Molecular Models of Hydroxide, Oxyhydroxide and Clay Phases and the Development of a General Force Field. J. Phys. Chem. B 2004, 108, 1255-1266.

(64) Pouvreau, M.; Greathouse, J. A.; Cygan, R. T.; Kalinichev, A. G. Structure of Hydrated Gibbsite and Brucite Edge Surfaces: DFT Results and Further Development of ClayFF Classical Force Field with Metal-O-H Bending Terms. J. Phys. Chem. C 2017, 121, 1475714771.

(65) Pouvreau, M.; Greathouse, J. A.; Cygan, R. T.; Kalinichev, A. G. Structure of Hydrated Kaolinite Edge Surfaces: DFT Results and Further Development of ClayFF Classical Force Field with Metal-OH Angle Bending Terms. J. Phys. Chem. C 2019, 123, 11628-11638.

(66) Cygan, R. T.; Romanov, V. N.; Myshakin, E. M. Molecular Simulation of Carbon Dioxide Capture by Montmorillonite Using an Accurate and Flexible Force Field. J. Phys. Chem. C 2012, 116, 13079-13091.

(67) Martin, M. G.; Siepmann, J. I. Transferable Potentials for Phase Equilibria. 1. United-Atom Description of n-Alkanes. J. Phys. Chem. B 1998, 102, 2569-2577.

(68) Plimpton, S. J.; Pollock, R.; Stevens, M. J. In Particle-Mesh Ewald and rRESPA for Parallel Molecular Dynamics Simulations, Proceedings of the Eigth SIAM Conference on Parallel Processing for Scientific Computing, Minneapolis, Minnesota, 1997.

(69) Tribello, G. A.; Bonomi, M.; Branduardi, D.; Camilloni, C.; Bussi, G. Plumed 2: New Feathers for an Old Bird. Comput. Phys. Commun. 2014, 185, 604-613.

(70) Peng, D. Y.; Robinson, D. B. A New Two-Constant Equation of State. Ind. Eng. Chem. Fundam. 1976, 15, 59-64.

(71) Criscenti, L. J.; Cygan, R. T. Molecular Simulations of Carbon Dioxide and Water: Cation Solvation. Environ. Sci. Technol. 2013, 47, $87-94$.

(72) Wang, J.; Kalinichev, A. G.; Kirkpatrick, R. J.; Cygan, R. T. Structure, Energetics and Dynamics of Water Adsorbed on the Muscovite (001) Surface: A Molecular Dynamics Simulation. J. Phys. Chem. B 2005, 109, 15893-15905. 
(73) Chong, L.; Myshakin, E. M. The Effect of Residual Water Content on Preferential Adsorption in Carbon Dioxide - Methane Illite Clay Minerals: A Molecular Simulation Study. Fluid Phase

Equilib. 2020, 504, No. 112333. 